\title{
Comprehensive analysis of relationship between vegetation attributes and soil erosion on hillslopes in the Loess Plateau of China
}

\author{
Jian Hou $\cdot$ Bojie Fu $\cdot$ Shuai Wang $\cdot$ \\ Huoxing Zhu
}

Received: 13 June 2013/ Accepted: 15 January 2014/Published online: 6 February 2014

(C) Springer-Verlag Berlin Heidelberg 2014

\begin{abstract}
In soil and water conservation research, vegetation is considered to be a primary factor affecting soil erosion. Many studies focus on the relationship between soil erosion and a given attribute of vegetation. Few studies have attempted a comprehensive analysis of vegetation attributes. Thus, the aim of this study is to explain the relationship between vegetation and soil erosion in detail. We studied 104 vegetation plots and 104 soil samples in the Yangjuangou catchment, Loess Plateau, Shaanxi Province, China. According to a correlation analysis of the vegetation attributes and soil ${ }^{137} \mathrm{Cs}$ inventories, vegetation cover exerts a positive effect on soil erosion. In addition, vegetation aggregation increases with increasing soil loss. During this period of study, plant diversity can have different relationships with soil erosion according to the vegetation pattern. When vegetation distribution is relatively homogeneous, plant cover decreases with increasing diversity, and the soil loss increases. When vegetation pattern distributes between homogeneous and heterogeneous, the relationship between vegetation diversity and soil erosion is not obvious. When vegetation distribution is in a heterogeneous pattern, cover increases with increasing diversity, and soil loss decreases.
\end{abstract}

Keywords Vegetation coverage - Vegetation diversity . Vegetation pattern $\cdot$ Soil ${ }^{137} \mathrm{Cs}$ inventory $\cdot$ Soil erosion

\footnotetext{
J. Hou · B. Fu ( $₫) \cdot$ S. Wang $\cdot$ H. Zhu

State Key Laboratory of Urban and Regional Ecology, Research Center for Eco-Environmental Sciences,

Chinese Academy of Sciences, P. O. Box 2871,

Beijing 100085, China

e-mail: bfu@rcees.ac.cn

J. Hou

e-mail: amatum@126.com
}

\section{Introduction}

As a primary cause of land degradation, soil erosion is an important ecological problem throughout the world (Boardman 2006). Recently, due to the effect of land degradation on economic development, food supply and floods, soil erosion has attracted more attention than before (Zuazo and Pleguezuelo 2009). In ecologically fragile arid and semi-arid areas, it is especially important to study and manage soil erosion.

Most studies investigated soil erosion through erosion plot monitoring. The advantages of this method are that it is accurate and easy to calculate soil erosion. However, several of its disadvantages should not be discounted. For example, erosion plots have a maximum service life of approximately 5 years and can monitor soil erosion only in the short term, due to the exhaustion of available material within the plot and the lack of input material from outside (Boix-Fayos et al. 2006). Therefore, this method cannot provide the related information for long periods of time. In addition, erosion plots are difficult to build and monitor for large samples.

During the last few years, the use of environmental tracers, particularly ${ }^{137} \mathrm{Cs}$, has allowed advances in the quantitative evaluation of soil erosion ( $\mathrm{Fu}$ et al. 2009; Zhang et al. 2003). This method makes use of the global fallout of bomb-derived radiocaesium from the period from 1950 s to 1970 s. When ${ }^{137}$ Cs falls to land, it is rapidly and strongly adsorbed by soil and moves with the transport of soil particles, which makes it possible to estimate soil loss or accumulation by measuring the spatial distribution of ${ }^{137} \mathrm{Cs}$ (Porto et al. 2001). The greater the soil inventory of ${ }^{137} \mathrm{Cs}$ in a site, the more sediment the site has accumulated. In contrast, a site with lower ${ }^{137} \mathrm{Cs}$ has lost more sediment to transport out of the site. 
There are many empirical and theoretical conversion models, such as the mass balance model (MBM) and the simplified mass balance model (SMBM) (Fu et al. 2009), that derive estimates of soil loss from measurements of the soil ${ }^{137}$ Cs inventory (Parsons and Foster 2011; Porto et al. 2001). Different models incorporate different specific sets of parameters. These models differ in the underlying assumptions and process descriptions they use to address uncertainties (Porto et al. 2001). To prevent mistakes from complex model conversion, some conversion models were not used to quantitatively estimate soil loss. Instead, the original data on the soil ${ }^{137} \mathrm{Cs}$ inventory within each plot was used to compare soil erosion among plots.

Soil erosion can be affected by many factors from the plot scale to the watershed scale. For instance, microtopography, soil conditions and vegetation can determine erosion on the hillslope scale, and climate, geomorphological conditions, land cover and land use may be drivers on the watershed scale. Hillslope is an important geographical unit on which many surface processes develop. Therefore, many studies have been conducted to control soil erosion on the hillslope scale.

Attempts to control soil erosion on hillslopes have included engineering, biological, and management methods (Lacombe et al. 2008; Marage 2011; Valentin et al. 2005). With respect to biological measures, there have been many studies of the relationship between vegetation and soil erosion conducted in arid and semi-arid areas because vegetation plays an important role in all aspects of the soil erosion process (Martin et al. 2010).

First, several studies on the relationship between vegetation cover and soil erosion on slopes have found that following an increase in vegetation cover, soil erosion decreases (Marques et al. 2007; Zhou et al. 2008). In a review of studies on the correlation between runoff volume and vegetation coverage throughout the world, Puigdefabregas (2005) concluded that the relationship between vegetation cover and runoff volume is usually a negative correlation extending from linear (Greene et al. 1994; Kainz 1989) to exponential (Marston 1952).

Second, vegetation patterns can have different effects on soil erosion (Puigdefabregas 2005). Compared with vegetation cover, vegetation pattern refers to plants distribution. Different soil erosion processes may take place with similar vegetation cover, but different vegetation patterns. Increasingly, studies have examined the dynamics of vegetation patterns along hillsides with soil erosion (Cerda 1997; Saco et al. 2007; Hiernaux and Gérard 1999). For example, after long-term monitoring in southeastern Spain, Boix-Fayos et al. (2007) determined that soil erosion differed in intensity across areas that varied mostly by different vegetation patterns. Ludwig et al. (2007) conducted a study in northeastern
Australia and suggested that soil erosion intensity is stronger where the vegetation pattern is heterogeneous than where it is homogeneous.

Third, the relationship between vegetation diversity and soil erosion is ambiguous (Bautista et al. 2007). Although it has frequently been observed that vegetation diversity is positively correlated with soil erosion, some other studies found a negative correlation between the two (Turnbull et al. 2008). In research on the hillslope scale in the Netherlands, Martin et al. (2010) found that the correlation between vegetation diversity and soil erosion can differ in places with different vegetation. After a study of the effects of vegetation cover and diversity on soil erosion in southeastern Spain, Bautista et al. (2007) suggested that the effect of vegetation diversity on soil erosion may be masked by the vegetation pattern. Thus, it is suggested that the relationship between vegetation diversity and soil erosion can be presented more obviously in the same vegetation pattern than in different vegetation pattern.

In addition to vegetation cover, pattern and diversity, other vegetation characteristics have also been considered: for example, whether vegetation height has an effect on soil erosion has been tested by several researchers (Xu et al. 2006; Zhang et al. 2006). Litter can also play an important role on soil erosion by changing the soil structure around plants (Thurow et al. 1986). In addition, a negative exponential correlation between vegetation root density and soil erosion intensity was found by Gyssels and Poesen (2003) in Belgium. As a whole, this research suggests that in studies of the relationship between vegetation and soil erosion, the trend is now to conduct comprehensive analyses of vegetation attributes and dynamics. However, recently few researchers perform a comprehensive analysis of them, and such a study is needed to explain the relationship between vegetation and the soil erosion in detail.

By investigating experiments on plots on a mountain slope located in Loess Plateau of China, which has a typical semi-arid continental climate, this research attempted to deal with the following two questions: (1) is there a significant correlation between all pairs of vegetation coverage, pattern, diversity and soil erosion? (2) If the relationship between vegetation diversity and soil erosion cannot be observed with different vegetation patterns, whether the relationship can be presented with similar vegetation patterns? This research is helpful in understanding the relationship between vegetation attributes (coverage, diversity and pattern) and soil erosion. In addition, this research can be of practical significance by providing information for water and soil conservation and land management. 


\section{Materials and methods}

Study area

This research was carried out in the Yangjuangou catchment $\left(36^{\circ} 42^{\prime} \mathrm{N}, 109^{\circ} 31^{\prime} \mathrm{E}\right)$ of the Loess Plateau in Shaanxi Province (Fig. 1). After "Grain-For-Green" project carried out in this area, far greater areas of farmland were transformed into grassland and began to be second in succession in this place (Zhang et al. 2013). The Yangjuangou catchment has a semi-arid continental climate. The mean annual precipitation in this catchment is $535 \mathrm{~mm}$ and the mean annual air temperature is $10.6{ }^{\circ} \mathrm{C}$ from 1988 to 2007 , according to data from the city's meteorological station. The elevation of Yangjuangou catchment ranges from 1,050 to $1,298 \mathrm{~m}$ (Liu et al. 2012). Rainfall in the Yangjuangou catchment is concentrated between June and September, and causes most of the soil erosion in the catchment. So, water erosion is the main erosion style in this catchment. Usually, the composition of soil in the Yangjuangou catchment is more than $50 \%$ silt $(0.002-0.05 \mathrm{~mm})$, and $<20 \%$ clay $(<0.002 \mathrm{~mm})$, with a porosity of nearly $50 \%$ (Liu et al. 2012).

\section{Field test}

From July to September 2012, 104 plots were investigated throughout the Yangjuangou catchment, examining several factors that can influence soil erosion on hillsides. All plots had similar soil composition, climate, geomorphology and land use, but the vegetation varied. The locations of the plots were selected according to three common conditions: first, all the plots were located in fields that had been abandoned for nearly 60 years, as confirmed by personal interviews with landowners and managers. Second, all the plots had a slope between $25^{\circ}$ and $32^{\circ}$, and a southwestern aspect. Third, these 104 plots were all located in the middle slope. In addition, the precipitation in every plot location was similar because they fell within a catchment of no more than $2.02 \mathrm{~km}^{2}$. Thus, vegetation should be the key factor affecting interrill soil erosion in the plots.

Each plot was a $2 \mathrm{~m}$ square. The relative position, coverage area and height of each plant were recorded within each plot (Fig. 1e). A Cartesian coordinate system was established for each plot. The relative position was recorded as the coordinate value of each plant for all plots. Coverage area was calculated by measuring the crown diameter of plant. And the height of each plant was directly measured by the ruler. In addition, some basic attributes (life form, average height and abundance in plots) of all plants species in our research were recorded (Table 1). Because the counts of liverworts, mosses and stones were so low within plots, they were unlikely to have a strong influence on soil erosion, and so were not recorded. Soil samples were collected at a sampling depth of $0-40 \mathrm{~cm}$ with a soil auger having an internal diameter of $0.028 \mathrm{~m}$. Three randomly placed samples were collected near plants within each plot, and mixed together before analyzing the soil ${ }^{137} \mathrm{Cs}$ inventory in the laboratory (Fig. 1f).

\section{Laboratory tests}

After being air-dried in a hood and sieved through a 2-mm screen, the soil samples were weighed on a balance. Then, using an HPGe co-axial detector coupled to a multichannel analyzer, the soil ${ }^{137} \mathrm{Cs}$ inventory in the samples was measured. To minimize the uncertainties associated with the precision of ${ }^{137} \mathrm{Cs}$ measurements, the activity of ${ }^{137} \mathrm{Cs}$ was detected at $662 \mathrm{keV}$ with a counting time of approximately $30,000 \mathrm{~s}$. This test provided results which were at least $90 \%$ reliable at the $95 \%$ confidence level. In addition, the specific activity was calculated by reference to standards (Fu et al. 2009).

It is found that 16 soil samples did not have a ${ }^{137} \mathrm{Cs}$ inventory value. It is suggested that severe erosion may have taken place at those sampling sites, after excluding the error introduced during the sampling procedure. Those samples were excluded.

\section{Vegetation data processing}

A cylindrical model was established for every plant in each plot (Fig. 1g). The location of the axis of the cylinder represents the location of a plant within plot. The crosssectional area of the cylinder represents the cover area of a plant in the plot (Fig. 1h). If plants overlapped, they were treated as a single axis. Based on these cylindrical models, the coverage area and pattern of the vegetation in a horizontal plane can be obtained. Vegetation attributes were measured as follows.

\section{Total area of vegetation coverage}

Total area of vegetation coverage (TA) is used to measure vegetation coverage area in each plot, and this index was calculated by adding up the cross-sectional area of the cylinder model. If the coverage areas overlapped, they were treated as one.

\section{Aggregation index}

Different from TA, aggregation index (AI) was used to express the vegetation pattern. The AI was computed as an area-weighted mean class aggregation index for each plot. $\mathrm{AI}$ is scaled to account for the maximum possible number 


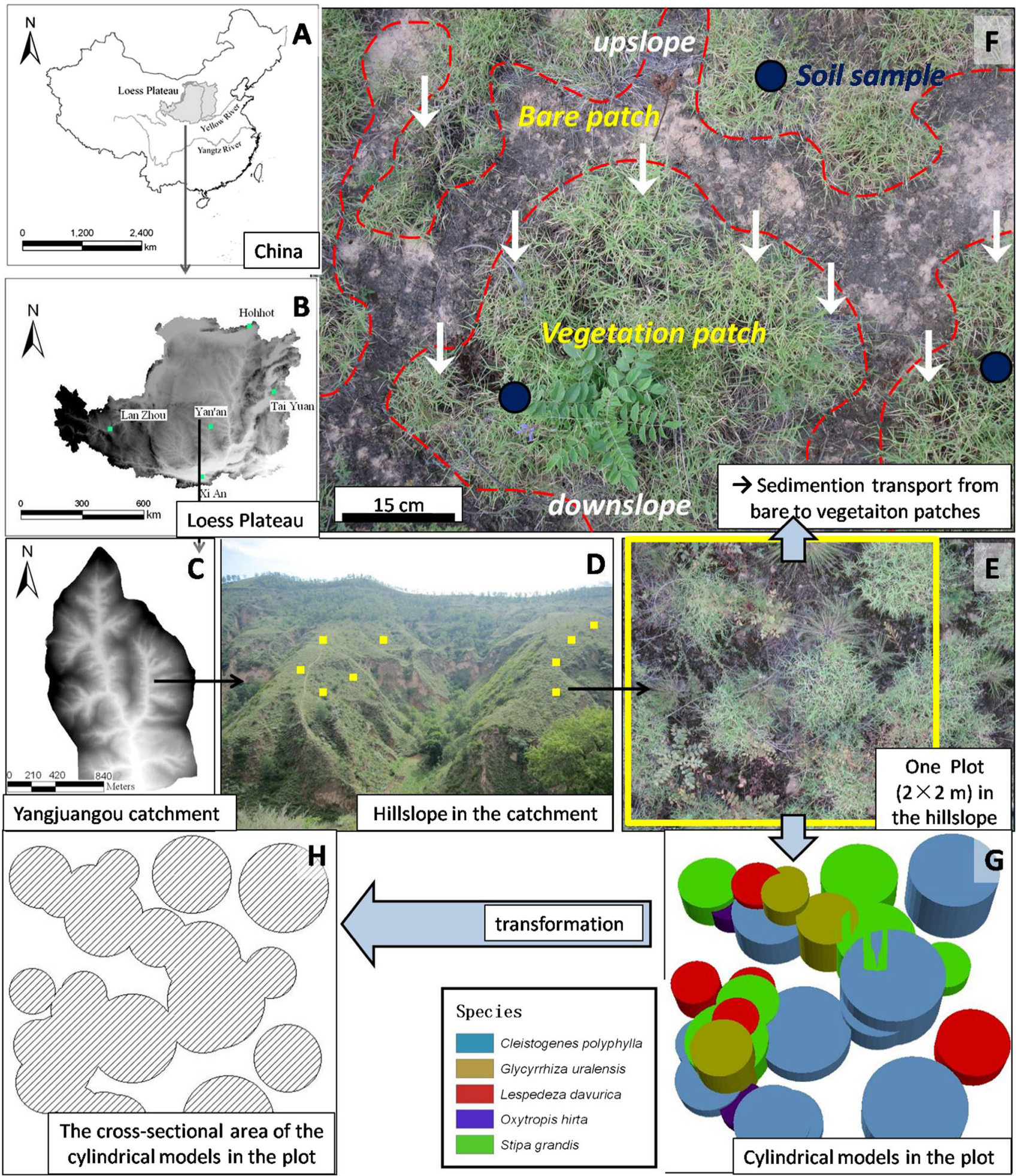

Fig. 1 A series of graphs to explain our research. a-e Location of a plot in our research; $\mathbf{f}$ vegetation patches can retain soil particle from surrounding areas. More severe erosion taken place in the bare patches can result in more sediment, with nutrients and water, accumulated in vegetation patches. Vegetation patches can develop bigger and bigger in this way. And, bigger vegetation patches can retain more sediment. This is a feedback. Soil samples were collected near plants. $g$ Location of the axis of the cylinder indicates a plant's location in the plot. The cross-sectional area of a cylinder model is the cover area of a plant in the plot. If there was an overlap between plants, the overlap was combined into one. The height of a cylinder indicates a plant's height; $\mathbf{h}$ the cross-sectional area of the cylinder models is the total area of vegetation coverage (TA) in the plot. Aggregation index (AI) of the vegetation patches can be calculated with raster graph transformed from this graph 
Table 1 The attributes of the plant species in plots

\begin{tabular}{|c|c|c|c|}
\hline Species & Life form & Average height $(\mathrm{cm})$ & Average abundance \\
\hline Artemisia dalai-lamae & Perennial forb & 20 & 4.06 \\
\hline Artemisia giraldii & Perennial sub-shrub & 36 & 19.53 \\
\hline Artemisia sacrorum & Perennial sub-shrub & 30 & 29.40 \\
\hline Artemisia scoparia & Biennial sub-shrub & 19 & 1.36 \\
\hline Bothriochloa ischcemum & Perennial grass & 24 & 19.91 \\
\hline Bupleurum chinense & Perennial forb & 21 & 0.45 \\
\hline Calamagrostis pseudophragmites & Perennial grass & 31 & 1.67 \\
\hline Carex korshinskii & Perennial grass & 13 & 35.72 \\
\hline Cirsium setosum & Perennial forb & 17 & 0.14 \\
\hline Cleistogenes polyphylla & Perennial grass & 14 & 3.92 \\
\hline Cleistogenes squarrosa & Perennial grass & 17 & 8.32 \\
\hline Euphorbia esula & Perennial forb & 20 & 0.74 \\
\hline Euphorbia humifusa & Perennial forb & 3 & 0.26 \\
\hline Geranium pratense & Perennial forb & 11 & 0.30 \\
\hline Glycyrrhiza uralensis & Perennial sub-shrub & 35 & 1.60 \\
\hline Helictotrichon schellianum & Perennial grass & 21 & 1.13 \\
\hline Heteropappus altaicus & Perennial forb & 18 & 5.86 \\
\hline Ixeridium sonchifolium & Perennial forb & 9 & 1.92 \\
\hline Lespedeza davurica & Perennial sub-shrub & 24 & 48.83 \\
\hline Lespedeza floribunda & Perennial sub-shrub & 26 & 1.72 \\
\hline Linum stelleroides & Biennial sub-shrub & 12 & 0.44 \\
\hline Melilotus alba & Biennial sub-shrub & 55 & 1.97 \\
\hline Oxytropis bicolor & Perennial forb & 4 & 0.50 \\
\hline Oxytropis hirta & Perennial forb & 5 & 2.70 \\
\hline Paeonia suffruticosa & Perennial forb & 22 & 0.93 \\
\hline Patrinia heterophylla & Perennial forb & 21 & 3.81 \\
\hline Patrinia scabiosaefolia & Perennial forb & 23 & 15.09 \\
\hline Polygala tenuifolia & Perennial forb & 12 & 5.85 \\
\hline Potentilla bifurca & Perennial forb & 6 & 3.17 \\
\hline Potentilla tanacetifolia & Perennial forb & 7 & 7.35 \\
\hline Serratula centauroides & Perennial forb & 19 & 0.30 \\
\hline Siphonostegia chinensis & Annual forb & 24 & 0.50 \\
\hline Stipa grandis & Perennial grass & 39 & 22.68 \\
\hline Taraxacum mongolicum & Perennial forb & 15 & 0.02 \\
\hline Themeda japonica & Perennial grass & 31 & 3.57 \\
\hline Vicia cracca & Perennial forb & 13 & 2.28 \\
\hline Viola dissecta & Perennial forb & 15 & 4.25 \\
\hline Viola philippica & Perennial forb & 11 & 2.83 \\
\hline
\end{tabular}

of similar joins in any given landscape composition (He et al. 2000).

$$
\mathrm{AI}=100\left(\frac{g_{\mathrm{ii}}}{\max \_g_{\mathrm{ii}}}\right)
$$

$g_{\mathrm{ii}}=$ number of similar joins between pixels of patch class $\mathrm{i}$ in a raster graph. $\max \_g_{\text {ii }}=$ maximum number of similar joins between pixels of patch class $i$ in a raster graph.
In this research, we first transform vegetation patches to raster graphs for all plots (Fig. 1h). Second, all vegetation patches within plots were regarded as one class, though vegetation patches are often composed by different plant species. AI values range from 0 to 100 , where 0 represents patches that are maximally disaggregated. AI increases as the landscape becomes increasingly aggregated and reaches 100 when the landscape consists of only a single patch (He et al. 2000). 
Shannon's diversity index

Shannon's diversity index (SHDI) was used to evaluate vegetation species diversity (Riis and Hawes 2002). In the calculation of landscape diversity, SHDI equals minus the sum, across all patch types, of the proportional abundance of each patch type, multiplied by its proportion. The formula is as followed:

$\mathrm{SHDI}=-\sum_{i=1}^{m}\left(P_{i} \ln P_{i}\right)$

$P_{i}$ is the proportion of the landscape occupied by patch type (class) $i$. In this study, in order to evaluate vegetation species diversity, each species was converted into one patch type, and the areas of each patch are equal. By this method, the value of SHDI, calculated in landscape diversity, is equal to the value of the SHDI, used in vegetation species diversity. SHDI equals 0 when a landscape, in this case a plot, contains only one patch type. The SHDI increases as the number of patch types increases in a landscape, but this index has no upper limit. This index was calculated for all 88 plots.

\section{Data analysis}

Prior to data analysis, Shapiro-Wilk normality test has been used to check the normal distribution of the data. In this research, it is found that the data are approximate normal distribution in each dataset (Shapiro-Wilk normality test: $p>0.05$ ) and do not need a transformation.

First, a statistical analysis was conducted for soil and vegetation data in all plots. Pearson's correlation tests were calculated between every pair of soil ${ }^{137} \mathrm{Cs}$ inventory, TA, AI and SHDI for all plots. Single factor regressions were used to analyze the relationship between each pair of TA, AI and SHDI.

Second, in order to observe the relationship between vegetation diversity and soil erosion for similar vegetation patterns, all the 88 plots were arranged in the order of descending value of AI. Then, the 88 plots were divided into 8 sub-groups (sub-groups 1 through 8 ) with 11 plots each, according to the order of descending value of AI, with minimum AI values in sub-group 1 and maximum in sub-group 8. In this way, AI values will be more similar in sub-groups than in all plots, and there are enough sample sizes (11 plots) within a sub-group to make a regression analysis between soil ${ }^{137} \mathrm{Cs}$ inventory and SHDI. Within each sub-group, single factor regressions were conducted between SHDI and soil ${ }^{137}$ Cs inventory, and between SHDI and TA. It is suggested that this grouping method is suitable for statistical analysis, and the difference of AI values within a sub-group is smaller enough to observe the
Table 2 Mean value/standard deviation for total area of vegetation coverage (TA), aggregation index (AI), Shannon's diversity index (SHDI) and species richness for plots in each sub-group

\begin{tabular}{llllc}
\hline Sub-group & TA $\left(\mathrm{m}^{2}\right)$ & AI & SHDI & Species richness \\
\hline 1 & $2.39 / 0.28$ & $97.09 / 0.36$ & $1.99 / 0.38$ & $10.91 / 3.05$ \\
2 & $2.19 / 0.18$ & $96.38 / 0.19$ & $1.83 / 0.25$ & $9.91 / 2.91$ \\
3 & $2.12 / 0.23$ & $95.75 / 0.25$ & $2.01 / 0.63$ & $12.45 / 5.92$ \\
4 & $2.11 / 0.18$ & $95.27 / 0.06$ & $1.86 / 0.37$ & $10.91 / 3.65$ \\
5 & $1.97 / 0.31$ & $95.04 / 0.11$ & $1.81 / 0.34$ & $11.64 / 3.07$ \\
6 & $1.96 / 0.19$ & $94.74 / 0.08$ & $2.02 / 0.49$ & $13.55 / 4.84$ \\
7 & $1.83 / 0.23$ & $94.31 / 0.17$ & $1.76 / 0.44$ & $11.64 / 4.61$ \\
8 & $1.72 / 0.14$ & $93.37 / 0.66$ & $1.59 / 0.27$ & $9.36 / 1.86$ \\
\hline
\end{tabular}

relationship between vegetation diversity and soil erosion. In addition, mean value and standard deviation for TA, AI, SHDI and species richness for plots were measured within each sub-group (Table 2).

For this study, the vegetation cylindrical models were built using ArcGis9.2. TA, AI and SHDI were calculated by Fragstats3.3. Shapiro-Wilk normality test, Pearson's correlation test and single factor regression were conducted with SPSS17.0. Soil ${ }^{137}$ Cs inventory was analyzed with the software that accompanies the HPGe co-axial detector.

\section{Results}

Statistical analysis for all plots

Among vegetation attributes, significant positive correlations were found between all pairs of TA, AI and SHDI (Table 3). Moreover, the results of Pearson's correlation tests between soil ${ }^{137} \mathrm{Cs}$ inventory and the attributes of vegetation show that there is a significant positive correlation between soil ${ }^{137} \mathrm{Cs}$ inventory and both TA $(p<0.001)$ and $\mathrm{AI}(p<0.001)$. The correlation between soil ${ }^{137} \mathrm{Cs}$ inventory and SHDI was not significant $(p=0.158$, Table 3$)$.

In addition, the single factor regression between soil ${ }^{137} \mathrm{Cs}$ inventory and TA revealed an exponential distribution (Fig. 2). The exponential distribution model was selected because it had the largest correlation index $\left(R^{2}=0.196\right)$ among the models. A linear regression was also conducted between soil ${ }^{137} \mathrm{Cs}$ inventory and $\mathrm{AI}$, and likewise selected this exponential distribution model because it had a larger correlation index $\left(R^{2}=0.138\right)$ than other models (Fig. 2).

Classification and cluster for all plots

Eight sub-groups were further classified into three groups (Groups A, B and C) according to the results of the single 
Table 3 Results of Pearson's correlation test for all plots

\begin{tabular}{llll}
\hline & ${ }^{137} \mathrm{Cs}$ & TA & AI \\
\hline TA & $0.428(p<0.001)^{* *}$ & 1 & 1 \\
AI & $0.372(p<0.001)^{* *}$ & $0.694(p<0.001)^{* *}$ & $0.214(p=0.045)^{*}$ \\
SHDI & $0.152(p=0.158)$ & $0.301(p=0.004)^{* *}$ & 0.214 \\
\hline
\end{tabular}

Parameter definitions: ${ }^{137} \mathrm{Cs}$ soil ${ }^{137} \mathrm{Cs}$ inventory, $T A$ total area of vegetation cover, AI aggregation index, SHDI Shannon's diversity index

* Significant correlation at level of 0.05

** Significant correlation at level of 0.01

Fig. 2 Results of single factor regression between soil ${ }^{137} \mathrm{Cs}$ inventory and the total vegetation area (TA) or vegetation aggregation index (AI) for all plots

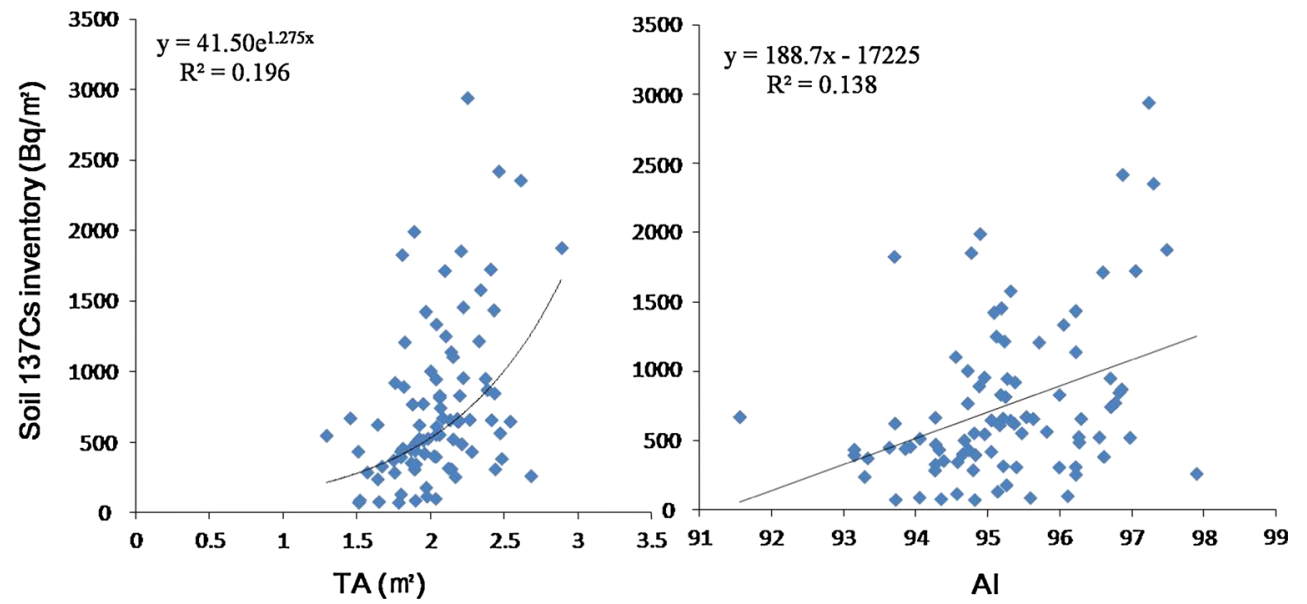

factor regressions within each sub-group. Group A contains the sub-groups 1 and 2 , with negative relationships between SHDI and soil ${ }^{137} \mathrm{Cs}$ inventory (sub-group 1, $R^{2}=0.380$; sub-group $2, R^{2}=0.429$ ), and between SHDI and TA (sub-group $1, R^{2}=0.43$; sub-group $2, R^{2}=0.67$ ); Group B contains the sub-groups 3, 4 and 5, with no significant relationships; and Group $\mathrm{C}$ contains the sub-groups 6, 7 and 8, with positive relationships between SHDI and soil ${ }^{137} \mathrm{Cs}$ inventory ( $R^{2}$ is from 0.371 to 0.757 ), and between SHDI and TA $\left(R^{2}\right.$ values are from 0.370 to 0.500 , Fig. 3).

\section{Discussion}

Relationship between soil erosion and vegetation

In this study, an exponential positive correlation between soil ${ }^{137} \mathrm{Cs}$ inventory and TA was observed for all plots (Fig. 2a). Because of the importance of vegetation coverage in preventing soil loss, as vegetation coverage increased, soil ${ }^{137} \mathrm{Cs}$ inventory increased as well. On one hand, vegetation canopies can intercept raindrops and prevent them from falling directly on the surface and creating erosion. On the other hand, high vegetation coverage implies a vegetation patch strong enough to capture soil particles transported by runoff from surrounding bare patches. So, with increasing of vegetation coverage, the higher the value of soil ${ }^{137} \mathrm{Cs}$ inventory, the lower the amount of soil erosion, and the higher the amount of soil accumulation near plants for all plots.

There is a linear positive correlation between soil ${ }^{137} \mathrm{Cs}$ inventory and AI for all plots (Fig. 2b). The increase of AI within a plot means that the pattern of vegetation implies a more heterogeneous vegetation distribution and more developed patch. The more developed a vegetation patch, the more soil particles the vegetation patch can intercept. So, along with AI, the soil ${ }^{137} \mathrm{Cs}$ inventory also increases as soil particles in runoff accumulate within a vegetation patch.

The relationship between soil ${ }^{137}$ Cs inventory and SHDI is not significant for all plots (Table 3). However, there is a positive relationship between SHDI and TA. Generally, with increasing vegetation coverage, species diversity increases, as has been documented in previous research (Ohsawa and Shimokawa 2011). In addition, there is also a positive relationship between SHDI and AI in this research. With increasing of AI, soil particles are increasingly transported from the nearby areas and trapped by the vegetation. At the same time, soil nutrients and water accumulate in the patch. The result is an increase in species diversity near existing plants. Thus, the relationship 


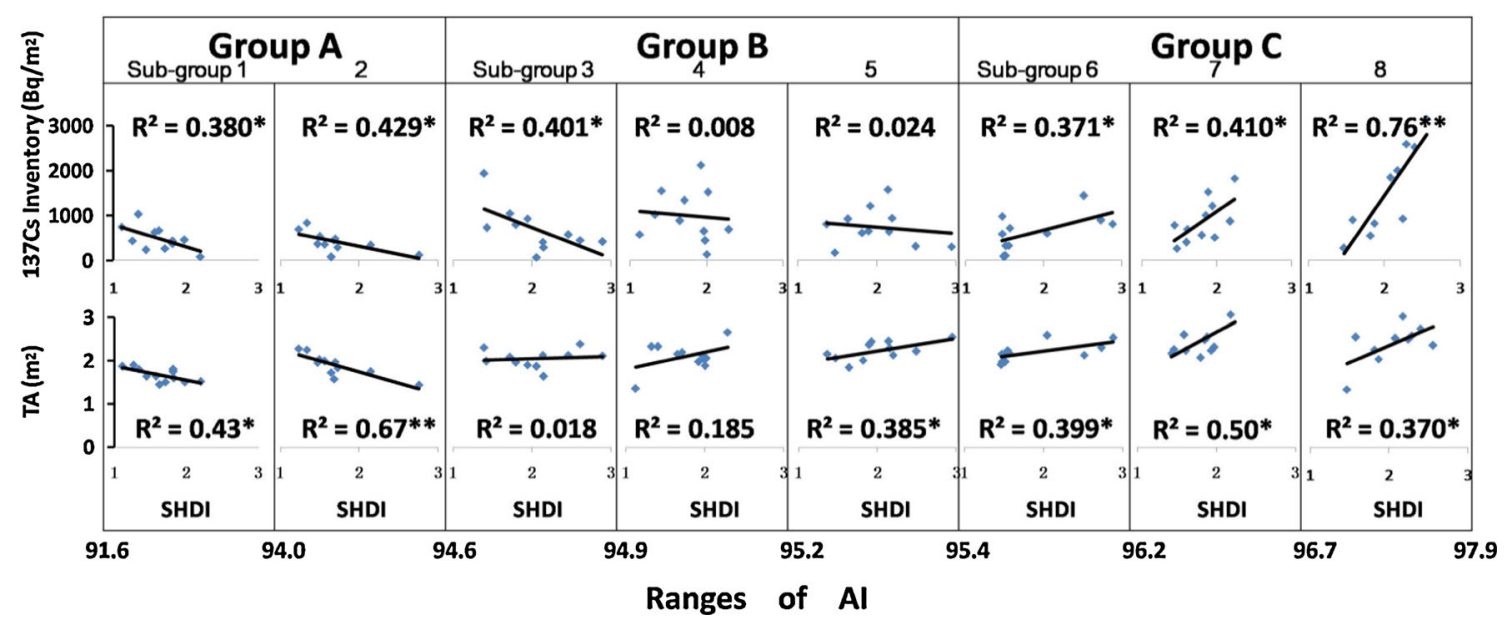

Fig. 3 Results of group for all plots according to the ranges of aggregation index (AI). Single factor regression analysis between TA and SHDI and between soil ${ }^{137} \mathrm{Cs}$ inventory and SHDI were carried

between soil ${ }^{137} \mathrm{Cs}$ inventory (indicating the amount of deposition) and SHDI (representing species diversity) may be masked by AI (vegetation pattern).

Relationship between soil erosion and vegetation under different conditions of vegetation pattern

To explain the relationship between the amount of soil erosion and species diversity, this relationship should be concurrently studied at various vegetation patterns from homogeneous to heterogeneous.

First, when vegetation distribution is relatively homogeneous, species diversity is negatively correlated with vegetation coverage and the amount of soil accumulation near plants, as found in Group A (Fig. 3). Under this condition, because of effect of vegetation on soil resources, soil resources are distributed in a homogeneous pattern. Species with various resource requirements within a community can occupy various niches (Anthwal et al. 2008). Species with different niches tend to live more closely than species with similar niches because of species competition (Anthwal et al. 2008). As a result, as diversity increases, the overlap among the different plant canopies increases, but the total area of vegetation contracts. Due to the effect of vegetation coverage on soil erosion, with decreased coverage, more soil particles are transported out of the vegetation patches, which lead to a decrease in particle accumulation near plants.

Second, when vegetation distributes between homogeneous and heterogeneous patterns, the relationship between species diversity and vegetation cover is unclear, as is the relationship to soil accumulation, as found in Group B (Fig. 3). Under this condition, it is suggested that the vegetation pattern is developing from a homogeneous to a heterogeneous distribution. Though the third sub-group of out within each sub-group; Based on the values of $R^{2}$, three groups were established; **significant correlation at level of 0.01 ; *significant correlation at level of 0.05 with Pearson's correlation test

Group B had an even more heterogeneous distribution, the heterogeneous vegetation patterns were already forming during the transitional phase. Therefore, it is not easy to find a straightforward relationship between vegetation species diversity and vegetation coverage or soil loss in Group B.

Third, when vegetation distribution is relatively heterogeneous, species diversity is positively correlated with vegetation coverage and the amount of soil accumulation near plants, as found in Group C (Fig. 3). Under this condition, within an aggregated vegetation patch, increases in diversity indicate that more habitats are occupied by species with different niches. Therefore, as diversity increases, vegetation coverage also increases (Fig. 3). Increasing vegetation cover leads to more soil particles from runoff originating in other patches getting intercepted. Therefore, soil particles accumulate near plants.

Relationship between vegetation development and soil erosion

In semi-arid areas where moisture limits vegetation growth, vegetation often develops from homogenous to heterogeneous pattern as a response to the lack of water from rainfall (Aguiar and Sala 1999; Hiernaux and Gérard 1999). Aguiar and Sala (1999) proposed that because of the limited precipitation, plants cannot grow in a homogeneous distribution. Instead, vegetation is heterogeneously distributed. This pattern of heterogeneous distribution is described as a patch aggregation pattern. In a heterogeneous distribution pattern, some habitats begin to lose their vegetation, and vegetation gradually becomes scarce (Reynolds et al. 1999). At the end of this cycle, the abandoned habitats become denuded inter-patches or bare patches. In other habitats where vegetation grows, a more 
productive cycle develops, resulting in vegetation patches. The vegetation patches that develop through this cycle may have strong growth despite limited precipitation because the patch can exploit not only the water and nutrients from the patch it occupies, but also from the bare patches nearby (Reynolds et al. 1999).

Odum (1994) proposed a model to express the development of an ecosystem and suggested that species diversity increases along with vegetation succession. However, several studies have been unable to replicate his results (Gosper et al. 2012). The relationship between species diversity and vegetation succession may differ across environments. In the Loess Plateau, China, many studies have demonstrated that, with the vegetation succession, species diversity increases (Guo et al. 2010; Hao et al. 2005; Tao et al. 2009).

These results suggest that before the heterogeneous distribution develops to maturity, the effect of diversity is mainly to develop the heterogeneous pattern. Once the mature heterogeneous distribution develops, diversity prevents soil erosion. Wang et al. (2011) also carried out a research in Loess Plateau and they found that with vegetation succession, soil structure recovers, and the ability of the soil to prevent soil erosion increases slowly. It is suggested that though vegetation succession can resist soil erosion, the process is complicated and slow (Wang et al. 2011).

\section{Vegetation and erosion dynamics in other systems}

Many other studies obtained conclusions concerning the relationship between vegetation and soil erosion that were similar to or different from the results obtained by this study. And, various factors have been demonstrated by different studies in different environments.

With respect to vegetation factors, vegetation cover, diversity, biomass and plant morphological characteristics are often considered. For example, in the ski resort Jakobshorn in Davos, Switzerland, $25 \times 25 \mathrm{~cm}$ plots with rainfall simulations were conducted by Martin et al. (2010) to investigate the effect of vegetation cover and diversity on soil erosion. The findings of this research support the view that with increasing vegetation diversity, interrill soil erosion intensity may decrease at disturbed sites in alpine ecosystems (Martin et al. 2010). It is possible that the ecosystems at disturbed alpine sites differ from this research site, where increasing diversity prevents erosion only after the heterogeneous vegetation distribution is mature (as in Group C).

Moreover, in a study of overgrazed rangeland in South Africa, Podwojewski et al. (2011) evaluated the effect of vegetation coverage on soil detachment using artificial rain on $1 \mathrm{~m}^{2}$ plots with different vegetation coverage. They found a negative relationship between the intensity of soil erosion and vegetation cover. And, there was also a negative relationship between vegetation biomass and the intensity of soil erosion (Podwojewski et al. 2011). Vegetation biomass is not considered in this research, based on the assumption cover and diversity could represent biomass. However, under some conditions this may be not true. This issue requires further attention in the future.

In addition, in the Dong Cao catchment in North Vietnam, Phan Ha et al. (2012) monitored soil erosion in $1 \mathrm{~m}^{2}$ microplots under different vegetation cover for 2 years. These researchers demonstrated that plant species with different morphological characteristics may have provided different levels of soil protection. Similar research was performed and similar results obtained in the Southern Alps in France by Burylo et al. (2011). Combined with our research, these results suggest that not only morphological characteristics of species, but also the vegetation pattern affect soil erosion.

With respect to geographical factors, slope and microtopography are often studied (Liu et al. 2011). For instance, in southern Shaanxi Province, China, El Kateb et al. (2013) conducted a field experiment with 33 erosion plots to compare the soil erosion under different vegetation cover and on different slopes. Their results showed that the greater the slope, the higher the soil erosion intensity, and that vegetation cover had a great effect on soil erosion (El Kateb et al. 2013). In our research, the slope of the plots ranged from $25^{\circ}$ to $32^{\circ}$. This study suggests that though soil erosion is initially driven by different slopes, soil erosion develops with the vegetation succession.

In addition, in the dry environment of Jornada, New Mexico, USA, Michaelides et al. (2009) carried out smallscale rainfall simulations to investigate the control of erosion dynamics by vegetation. Their results suggested that vegetation type and canopy density were the main factors controlling runoff and erosion because they directly influence local micro-topography beneath the vegetation patches (Michaelides et al. 2009). Micro-topography may be the mechanism connecting vegetation and soil erosion.

\section{Conclusions}

In this study, an exponential positive correlation between vegetation coverage and soil ${ }^{137} \mathrm{Cs}$ was determined. Vegetation cover has a negative effect on soil erosion. This is consistent with existing researches. In addition, there is a linear positive correlation between vegetation aggregation and the soil ${ }^{137} \mathrm{Cs}$ inventory beneath the plants. With the increasing degree of vegetation aggregation, increasing soil particles transport from surrounding areas to vegetation patches. 
Species diversity has a different relationship with erosion, depending on the vegetation pattern. When vegetation is relatively homogeneous in its distribution, vegetation coverage decreases with increasing plant diversity. As a result, soil erosion increases. When vegetation distribution is from homogenous to heterogeneous pattern, no relationship between vegetation diversity and soil erosion is apparent. With heterogeneous vegetation pattern, vegetation cover increases along with vegetation diversity, and erosion subsequently decreases.

Vegetation development and soil erosion processes on hillsides exhibit relatively independent dynamics and include many similarities. There are checks and balances between them as they develop together. In terms of the relationship between vegetation and soil erosion, no vegetation factor has an isolated effect on soil erosion; these parameters are interrelated. With vegetation succession, the interrelation between vegetation factors develops. And this development helps to control soil erosion.

Acknowledgments This work was funded by the State Forestry Administration (No. 201004058), National Natural Science Foundation of China (No. 40930528) and the CAS/SAFEA International Partnership Program for Creative Research Teams of "Ecosystem Processes and Services".

\section{References}

Aguiar MR, Sala OE (1999) Patch structure, dynamics and implications for the functioning of arid ecosystems. Tree 14:273-277

Anthwal S, Bhatt AB, Nautiyal BP, Anthwal A (2008) Vegetation structure, niche width, niche overlap and types of competition in temperate grazingland of Garhwal Himalaya, India. Environmentalist 28(3):261-273

Bautista S, Mayor ÁG, Bourakhouadar J, Bellot J (2007) Plant spatial pattern predicts hillslope runoff and erosion in a semiarid Mediterranean landscape. Ecosystems 10(6):987-998

Boardman J (2006) Soil erosion science: reflections on the limitations of current approaches. Catena 68(2-3):73-86

Boix-Fayos C, Martínez-Mena M, Arnau-Rosalén E, Calvo-Cases A, Castillo V, Albaladejo J (2006) Measuring soil erosion by field plots: understanding the sources of variation. Earth Sci Rev 78(3-4):267-285

Boix-Fayos C, Martnez-Mena M, Calvo-Cases A, Arnau-Rosalen E, Albaladejo J, Castillo V (2007) Causes and underlying processes of measurement variability in field erosion plots in Mediterranean conditions. Earth Surf Proc Land 32(1):85-101

Burylo M, Rey F, Bochet E, Dutoit T (2011) Plant functional traits and species ability for sediment retention during concentrated flow erosion. Plant Soil 353(1-2):135-144

Cerda A (1997) The effect of patchy distribution of Stipa tenacissima L. on runoff and erosion. J Arid Environ 36:37-51

El Kateb H, Zhang H, Zhang P, Mosandl R (2013) Soil erosion and surface runoff on different vegetation covers and slope gradients: a field experiment in Southern Shaanxi Province, China. Catena 105:1-10

Fu BJ, Wang YF, Lu YH, He CS, Chen LD, Song CJ (2009) The effects of land-use combinations on soil erosion: a case study in the Loess Plateau of China. Prog Phys Geogr 33(6):793-804
Gosper CR, Yates CJ, Prober SM, Parsons BC (2012) Contrasting changes in vegetation structure and diversity with time since fire in two Australian Mediterranean-climate plant communities. Austral Ecol 37(2):164-174

Greene RSB, Kinnell PIA, Wood JT (1994) Role of plant cover and stock trampling on runoff and soil erosion from semi-arid wooded rangelands. Aust J Soil Res 32:953-973

Guo M, Zheng F, He W, An S, Liu Y, An J (2010) Variation of vegetation diversity and its relationship with soil nutrient and enzyme activity in lands of different abandoned years in the loess hilly-gully region. Acta Pedol Sin 47(5):979-986

Gyssels G, Poesen J (2003) The importance of plant root characteristics in controlling concentrated flow erosion rates. Earth Surf Proc Land 28(4):371-384

Hao W, Liang Z, Chen C, Tang L (2005) Study of species diversity evolvement process during vegetation restoration of abandoned farmland in the hilly loess plateau. Pratacultural Sci 22(9):1-8

He HS, Dezonia BE, Mladenoff DJ (2000) An aggregation index (AI) to quantify spatial patterns of landscapes. Landscape Ecol 15:591-601

Hiernaux P, Gérard B (1999) The influence of vegetation pattern on the productivity, diversity and stability of vegetation: the case of 'brousse tigrée' in the Sahel. Acta Oecol 20(3):147-158

Kainz M (1989) Runoff, erosion and sugar beet yields in conventional and mulched cultivation results of the 1988 experiment. Soil Technol 1:103-114

Lacombe G, Cappelaere B, Leduc C (2008) Hydrological impact of water and soil conservation works in the Merguellil catchment of central Tunisia. J Hydrol 359(3-4):210-224

Liu XH, He BL, Li ZX, Zhang JL, Wang L, Wang Z (2011) Influence of land terracing on agricultural and ecological environment in the loess plateau regions of China. Environ Earth Sci 62(4):797-807

Liu Y, Fu B, Lü Y, Wang Z, Gao G (2012) Hydrological responses and soil erosion potential of abandoned cropland in the Loess Plateau, China. Geomorphology 138(1):404-414

Ludwig JA, Bartley R, Hawdon AA, Abott BN, McJannet D (2007) Patch configuration non-linearly affects sediment loss across scales in a grazed catchment in north-east Australia. Ecosystems 10(5):839-845

Marage D (2011) Promoting ecological engineering for restoration of biodiversity in temperate forests. Procedia Environ Sci 9: $118-123$

Marques MJ, Bienes R, Jimenez L, Perez-Rodriguez R (2007) Effect of vegetal cover on runoff and soil erosion under light intensity events. Rainfall simulation over USLE plots. Sci Total Environ 378(1-2):161-165

Marston RB (1952) General cover requirements for summerstorm runoff control on Aspen sites in Northern Utah. J Forest 50: 303-307

Martin C, Pohl M, Alewell C, Körner C, Rixen C (2010) Interrill erosion at disturbed alpine sites: effects of plant functional diversity and vegetation cover. Basic Appl Ecol 11(7):619-626

Michaelides K, Lister D, Wainwright J, Parsons AJ (2009) Vegetation controls on small-scale runoff and erosion dynamics in a degrading dryland environment. Hydrol Process 23(11): $1617-1630$

Odum EP (1994) The concern for loss of biodiversity. Medecin Veterinaire du Quebec 0 (SPEC. ISSUE):29-30

Ohsawa M, Shimokawa T (2011) Extending the rotation period in larch plantations increases canopy heterogeneity and promotes species richness and abundance of native beetles: implications for the conservation of biodiversity. Biol Conserv 144(12): 3106-3116

Parsons AJ, Foster IDL (2011) What can we learn about soil erosion from the use of 137Cs? Earth Sci Rev 108(1-2):101-113 
Phan Ha HA, Huon S, Henry des Tureaux T, Orange D, Jouquet P, Valentin C, De Rouw A, Tran Duc T (2012) Impact of fodder cover on runoff and soil erosion at plot scale in a cultivated catchment of North Vietnam. Geoderma 177-178:8-17

Podwojewski P, Janeau JL, Grellier S, Valentin C, Lorentz S, Chaplot $V$ (2011) Influence of grass soil cover on water runoff and soil detachment under rainfall simulation in a sub-humid South African degraded rangeland. Earth Surf Proc Land 36(7): 911-922

Porto P, Walling DE, Ferro V (2001) Validating the use of caesium137 measurements to estimate soil erosion rates in a small drainage basin in Calabria, Southern Italy. J Hydrol 248:93-108

Puigdefabregas J (2005) The role of vegetation patterns in structuring runoff and sediment fluxes in drylands. Earth Surf Proc Land 30(2):133-147

Reynolds JF, Virginia RA, Kemp PR, Soyza AG, Tremmel DC (1999) Impact of drought on desert shrubs: effects of seasonality and degree of resource island development. Ecol Soc America 69(1):69-106

Riis T, Hawes I (2002) Relationships between water level fluctuations and vegetation diversity in shallow water of New Zealand lakes. Aquat Bot 74(2):133-148

Saco PM, Willgoose GR, Hancock GR (2007) Eco-geomorphology of banded vegetation patterns in arid and semi-arid regions. Hydrol Earth Syst Sci 11:1717-1730

Tao Y, De-xiang W, Jin-xing Z, Qiang W, Yu-yang LIN (2009) Vegetation succession and species diversity dynamics of the plant communities in the loess hilly and gully region. J Northwest For Coll 24(5):10-15

Thurow TL, Blackburn WH, Taylor CA (1986) Hydrologic characteristics of vegetation types as affected by livestock grazing systems, Edwards Plateau, Texas. J Range Manage 39(6): 505-509
Turnbull L, Wainwright J, Brazier RE (2008) A conceptual framework for understanding semi-arid land degradation: ecohydrological interactions across multiple-space and time scales. Ecohydrology 1(1):23-34

Valentin C, Poesen J, Li Y (2005) Gully erosion: impacts, factors and control. Catena 63(2-3):132-153

Wang B, Liu GB, Xue S, Zhu BB (2011) Changes in soil physicochemical and microbiological properties during natural succession on abandoned farmland in the Loess Plateau. Environ Earth Sci 62(5):915-925

Xu XL, Ma KM, Fu BJ, Liu XC, Huang Y, Qi J (2006) Research review of the relationship between vegetation and soil loss. Acta Ecologica Sinica 26(9):3137-3143

Zhang XB, Zhang YY, Wen AB, Feng MY (2003) Assessment of soil losses on cultivated land by using the $137 \mathrm{Cs}$ technique in the Upper Yangtze River Basin of China. Soil Tillage Research 69:99-106

Zhang ZQ, Wang SP, Sun G, Xie BY (2006) Runoff and sediment yield response to vegetation change at multiple scales: a review. Acta Ecologica Sinica 26(7):2356-2364

Zhang BQ, Wu PT, Zhao XN, Wang YB, Gao XD (2013) Changes in vegetation condition in areas with different gradients (1980-2010) on the Loess Plateau, China. Environ Earth Sci 68(8):2427-2438

Zhou P, Luukkanen O, Tokola T, Nieminen J (2008) Effect of vegetation cover on soil erosion in a mountainous watershed. Catena 75(3):319-325

Zuazo VHD, Pleguezuelo CRR (2009) Soil-erosion and runoff prevention by plant covers: a review. Sustain Agric 28:65-86 